\title{
Analysis of the Impact of the Active Feedback on the Quality of Motor Learning in Athletics: Case of the Teaching of the Long Jump
}

\author{
Maher Mrayeh, Mohamed Sami Bouzid, Aymen Hawani \\ Higher Institute of Sport and Physical Education Tunis, Tunisia \\ Email: mrayeh.meher@gmail.com, med.sami.bouzid@gmail.com, hawani.aymen@yahoo.com
}

Received 25 March 2015; accepted 16 June 2015; published 19 June 2015

Copyright (C) 2015 by authors and Scientific Research Publishing Inc.

This work is licensed under the Creative Commons Attribution International License (CC BY). http://creativecommons.org/licenses/by/4.0/

\section{(c) (i) Open Access}

\section{Abstract}

The goal of our research is to test the effect related to the time of use of the technical and pedagogical feedback during the teaching act, or just after the delivery of the student, on the quality of young learner's motor learning during an athletic activity cycle. To do so, we conducted a study population. It consisted of two physical education teachers, not athletics, with professional experience of 5 years working in two preparatory schools with similar working conditions (the same sports infrastructure and the same class size in the order of 25). These two pedagogical frameworks were observed during the teaching of athletic activity, namely the long jump for students in the 7th base year. Indeed, the population of the observed learners belongs to the middle class; the average age is \pm 13 years old. They do not have the driving experience in terms of practice of the long jump. The measured height of students is between $1.25 \mathrm{~m}$ and $1.42 \mathrm{~m}$ and their body mass are between $44 \mathrm{~kg}$ and $56 \mathrm{~kg}$. The analysis of the results allowed us to see the importance of the feedback instrument introduced in the motor learning or after their achievements. This resulted in improved techniques of executions of the different elements of the jump and the quantitative performance of students in both classes. In fact, motor learning considers the feedback as a critical element of the pedagogical relationship, and therefore it should be one of the major concerns of teachers when they focus on the motor skills to be learned.

\section{Keywords}

Effect, the Time of Retroaction, Quality, Motor Learning 


\section{Introduction}

For years, researchers have developed several practical and teaching techniques to provide educational resources in order to have a better learning among learners. Several techniques and tools can be put at the service of sport and physical education, especially in the search for a quality of motor learning.

Indeed, if the practice is the essential first external condition of learning, feedback is definitely the second. The notion of "feedback", known as the vocation of "feedback" or feedback and reaction to the performance, was largely addressed by Fishman and Anderson (1971) as an educational teaching procedure which depended on the response driving one or more students for the purpose of providing information relating to the acquisition or construction of a motor skill.

The feedback is a crucial variable of motor learning, and as such, it can be considered as an excellent source of motivation for the learner (Brunelle, Spallanzani, Lord, \& Petiot, 1983; Petracek, 1978).

Similarly, it can be an effective way that provides information supporting the acquisition or integration of motor skills (Goldberger \& Gerney, 1986; Beebe, 1975; Prato, 1975). Other researchers note the importance of feedback in relation to the acquisitions of the students: what would be the strongest and most powerful variable controlling the performance and learning. Progress would be impossible without feedback and performance would decrease in the absence of this feedback.

As the teacher assigns learning goals to his students, the feedback becomes a major component of the educational relationship and efficiency of the teacher and his chances of success with students.

On his part, Ammons (1996), on his part, considers that the feedback exerts its effects on the speed of learning achieved by an individual, as well as their motivation. More the knowledge of the result is specific, faster is the improvement of the feedback, and all ready its effect will be less. Its effects would focus on improving the quality of the task and change in the learner's behavior (Piéron \& Devillers, 1980; Ryan, Connell, \& Deci, 1985).

Hence, the interest that we brought to the study of the impact of feedback on the effectiveness of motor learning EPS, and specifically, the effect of the time of its introduction in the teaching of athletic activity, namely the long jump, was addressed for the first time by the learners of two schools in the Grand Tunis area. In fact, feedback is considered as a key element in the teacher-student learning relationship and therefore it provides a valid assessment of the quality and effectiveness of learning acquired during teaching situations. However, if the student can, to some extent, assess certain components of his performance, he may ignore or misuse certain relevant information (Piéron, 1992).

Furthermore, feedback is intended to act on the above and justifies its exercise. In this sense it is a response and its corrective goal is clearly identified (Nicaise, Cogérino, Bios, \& Amorose, 2006). The term "correction” is charged with a specific meaning. In teaching, the teacher corrects learners' errors. In editing, correction aims to improve which makes it more readable. Conducting a feedback also seems to be related to the knowledge of the results and performance of knowledge (Magill, 2011). In fact, most studies on teaching feedback focused on the description of the behavior of the teacher in the learning situation. In the first step of research in EPS, researchers are primarily interested in the teacher and believed that the effectiveness of education depends on the teacher's competence. The qualitative analysis of its characteristics, personality, behavior and relationship with students should help in order to establish an "effective teacher profile" or says Durand (1992), to distinguish "good teachers and not so good".

Other studies note the feedback effects on the modification of the learner's behavior (Piéron \& Devillers, 1980), but is rarely that physical education teachers take into account the feedback forms and effective moments of intervention. Moreover, it seems that teachers use an improperly feedback into the learning process engine which acts negatively on the knowledge assimilation process (Galligan, LePard, Schneider, \& Zhou, 2000). So the principal question will be focused on determining the effect of the introduction of feedback during or at the end of the teaching of athletic activity: the long jump.

\section{Research Methodology}

\subsection{Purpose of the Research}

Our study falls within the framework of an assessment of the impact of the use of two moments of feedback on the quality of motor learning of students (in the 9th grade of basic education in the city of Tunis) during an ath- 
letic activity, namely the long jump.

\subsection{The Study Population}

To achieve this research, two physical education (PE) teachers, not athletics, who have master degree and have 5 -year experience, participated in our study. Both teachers are working in two preparatory schools with similar working conditions (the same sports infrastructure and the same number of students per class are in the order of 25). These two pedagogical frameworks were observed during the teaching of athletic activity, namely the long jump for students in the 7th base form. These two classes of students have an average age of about \pm 13 years old and belong to the middle class. They have no experience in motor sport in terms of the activity (long jump). The measured height of students is between $1.25 \mathrm{~m}$ and $1.42 \mathrm{~m}$ and their body mass are between $44 \mathrm{~kg}$ and $56 \mathrm{~kg}$.

\subsection{Characteristics of Videotaped Sessions}

To test the effect of the timing of the introduction of feedback (feedback during (F.D) or feedback after (F.A)) the learning engines of each teacher was observed for six learning sessions in the long jump. Each session consists of three teaching situations and lasts 50 minutes. Two evaluation sessions at the beginning and end of the cycle have been programmed. To become familiar with the presence of the experimenter, the selected teachers were tested for two sessions each.

\subsection{Performance Measuring Tools}

\section{Didactic Observing}

The observation will focus on the introduction of feedback times done by teachers to take its impact on the quality of student learning engine during a jump cycle length. The educational benefits of teachers and technical students will be recorded by JVC digital video camera (25 frames in PAL). The sessions were analyzed in full by the experimenter himself. Each of the sessions was viewed repeatedly to understand the context of implementation of the activity. Qualitative and quantitative data were collected through an observation checklist composed by technical elements describing the long jump. These steps have been translated in terms of success criteria translated themselves into easy indicators to identify and observe and therefore to judge.

\subsection{Statistical Procedures}

Values are given as averages and frequencies. For data analysis quantitatively, we compared the averages before and after a jump cycle length using a t-test. We also calculated the delta percentage: $\Delta \%=(\mathrm{T} 1-\mathrm{T} 0) / \mathrm{T} 0 \times 100$; $\mathrm{T} 0$ is equal to the average initial performance of the $\mathrm{T} 1$ and the average of the performance. We tested for all data the effect of the group and training. Because of the small initial differences of the groups, we used t-student analysis by using the pre-test values to determine significant differences between the adjusted post-test in groups. We also used the chi-square to compare frequencies. SPSS Version 16.0 "Statistical Program of Social Science" was used for all statistical analyses. The significance level was set at $\mathrm{p}<0.05$. In other words, the data obtained in this study underwent a double Statistical treatment: the first treatment to determine the quantitative differences (rate information) for the variable of the study was done using the Student's t-test; the second treatment to determine differences in feedback from the different dimensions was used by the chi-square (or chi 2). A significance level of 0.05 was set as acceptable.

\section{Quantitative Analysis of Performance of Pupils}

\section{The Average Performance of the Two Groups during the Test and Retest}

Referring to the Table 1, we can distinguish a remarkable improvement in the average quantitative performance achieved at the end of the cycle in the long jump by the two groups constituting the study population regardless to the employee feedback. However, it should be noted that the difference is very significant $(p<0.05)$ between the two moments of feedback used by PE teachers (Rate of increase in the first group is $12.7 \%$, and it is the order of $5.77 \%$ for the second group). Also the measure of effect employability gap between two types of feedback that used to show that after the execution of the task (FA) is more effective if the feedback is programmed during the learning process (F.A > F.D $(p=0.001)$ ). 
Table 1. Effect of feedback used on motor performance of learners.

\begin{tabular}{cccccc}
\hline & Test & Retest & Variation (\%) & T-test & Sig \\
\hline Feedback after execution (F. A. G1) & $2.99 \pm 0.52$ & $3.37 \pm 0.45$ & $12.7 \%$ & 7.27 & 0.0001 \\
Feedback during execution (F. D. G2) & $2.77 \pm 0.58$ & $2.93 \pm 0.55$ & $5.77 \%$ & 7.87 & 0.0001 \\
\hline
\end{tabular}

\section{Analysis of Qualitative Performance of Different Phases in the Long Jump}

It should be noted that for each phase of physical activity is the object of our analysis we opt for the qualitative evaluation of the indicators that make up the order to show the homogeneity of the two groups regarding the prerequisites practical experience with this activity.

\subsection{Analysis of the Quality of Execution of the First Phase of the Long Jump: The Momentum of Race}

\subsubsection{The Trajectory of the Run}

The analysis of the results indicated in Table 2, enables us to deduce that feedback, placed in or at the end of the motor learning process, generated a small improvement in the quality of the trajectory the run in both groups of students. This continued effectiveness between the two phases of learning is due to trace a straight line before a jumper $10 \mathrm{~m}$ in length in order to channel the race of the student. However, it should be noted that no significant difference in effect was observed between the two moments of feedback $(\mathrm{X} 2=0.222)$.

\subsubsection{The Nature of the Race}

Referring to statistical data listed in Table 3 we see that the two feedback used in the intervention of teachers with students have a positive effect on improving the nature of the race (the majority of students underwent a progress in the race and accelerated with a percentage of $68 \%$ and $88 \%$ respectively in G1 and G2). Although we see a level of importance to the improvement of the results in the two groups of students, the difference appears insignificant in relation to the effect of the two moments of feedback $(\mathrm{X} 2=2.928)$.

\subsubsection{Inter-Segmental Coordination}

According to the analysis of the value of KH2, which was indicated in Table 4, we revealed that feedback placed during or at the end of the learning process of a prime spot caused a slight improvement in inter-segmental coordination between the two moments of evaluation. This coordination is very important for young learners as it is connected to the neuromuscular system. In addition, there is no difference in effectiveness as regards the use of one or the other form of feedback on the motor parameter $(\mathrm{X} 2=0.5)$.

\subsubsection{Status of the Student during the Race}

Analysis of Table 5 distinguishes that feedback used during or after the execution of a motor task generates a very small increase on the status of the student during the race after six training sessions (52\% for the feedback after (F.A) and feedback during (F.D) 60\% of students are released during the run). This is explained by the fact that the learner needs a long duration to improve the status during the run, especially when the learner does not have the prerequisites for this athletic activity.

\subsubsection{Trampling before the Board}

According to the data stored in the Table 6, we see that trampling decrease in both groups between the test results and retest. The result is remarkable for the first group (G1) with $68 \%$ of students who have developed without trampling race, against $56 \%$ of the second group who has difficulties in the regularity of the run (trampling). However, it should be noted that the difference between the two points of intervention is not significant $(\mathrm{X} 2=2.922)$.

\subsection{Analysis of the Quality of Execution of the Second Phase of the Long Jump: Appeal}

\subsubsection{Placement of the Takeoff Foot}

The use of Table 7 allows us to conclude that the difference is significant $(\mathrm{X} 2=4.158, \mathrm{p}=0.05$ ) between 
Table 2. Impact of FA and FD on the quality of the racing line.

\begin{tabular}{ccccccc}
\hline & & & Straight & Not straight & Total & Square Khi \\
\hline $\begin{array}{c}\text { Initial performance } \\
\text { (TEST) }\end{array}$ & F.A (G1) & EP & $18(72 \%)$ & $7(28 \%)$ & $25(100 \%)$ & 0.44 \\
Feedback after & TEST & EP & $18(72 \%)$ & $7(28 \%)$ & $25(100 \%)$ & 3.388 \\
execution (F.A.G1) & RETEST & EP & $23(92 \%)$ & $2(8 \%)$ & $25(100 \%)$ & $25(100 \%)$ \\
$\begin{array}{c}\text { Feedback during } \\
\text { execution (F.D.G2) }\end{array}$ & TEST & EP & $20(80 \%)$ & $5(20 \%)$ & $25(100 \%)$ & 0.596 \\
$\begin{array}{c}\text { Final performance } \\
\text { (RETEST) }\end{array}$ & F.A (G1) & EP & $23(92 \%)$ & $2(8 \%)$ & $25(100 \%)$ & 0.222 \\
\hline
\end{tabular}

Table 3. The feedback effect on the nature of the race.

\begin{tabular}{cccccccccc}
\hline & & & Progressive accelerated & Chopped & Constant & slow & Total & Square Khi \\
\hline $\begin{array}{c}\text { Initial Performance } \\
\text { (TEST) }\end{array}$ & F.A (G1) & EP & $10(40 \%)$ & $7(28 \%)$ & $4(16 \%)$ & $4(16 \%)$ & $25(100 \%)$ & 3.378 \\
& F.D (G2) & EP & $15(60 \%)$ & $3(12 \%)$ & $5(20 \%)$ & $2(8 \%)$ & $25(100 \%)$ & \\
$\begin{array}{c}\text { Feedback after } \\
\text { execution (F.A.G1) }\end{array}$ & TEST & EP & $10(40 \%)$ & $728 \%$ & $416 \%$ & $4(16 \%)$ & $25100 \%$ & 5.89 \\
& RETEST & EP & $17(68 \%)$ & $5(20 \%)$ & $3(12 \%)$ & $0(0 \%)$ & $25(100 \%)$ & \\
$\begin{array}{c}\text { Feedback during the } \\
\text { execution (F.D.G2) }\end{array}$ & TEST & EP & $15(60 \%)$ & $3(12 \%)$ & $5(20 \%)$ & $2(8 \%)$ & $25(100 \%)$ & 6.19 \\
$\begin{array}{c}\text { Final performance } \\
\text { (RETEST) }\end{array}$ & F.A (G1) & EP & $17(68 \%)$ & $5(20 \%)$ & $3(12 \%)$ & $0(0 \%)$ & $25(100 \%)$ & 2.928 \\
\hline
\end{tabular}

Table 4. The feedback effect on inter-segmental coordination.

\begin{tabular}{ccccccc}
\hline & & & Synchronized & Desynchronized & Total & Square Khi \\
\hline $\begin{array}{c}\text { Initial Performance } \\
\text { (TEST) }\end{array}$ & F.A (G1) & EP & $12(48 \%)$ & $13(52 \%)$ & $25(100 \%)$ & 0.32 \\
Feedback after & TEST & EP & $12(48 \%)$ & $13(52 \%)$ & $25(100 \%)$ & 4.158 \\
execution (F.A.G1) & RETEST & EP & $19(76 \%)$ & $6(24 \%)$ & $25(100 \%)$ & $11(44 \%)$ \\
Feedback during the & TEST & EP & $14(56 \%)$ & $11(44 \%)$ & $25(100 \%)$ & 4.666 \\
$\begin{array}{c}\text { execution (F.D.G2) } \\
\text { Final Performance } \\
\text { (RETEST) }\end{array}$ & RETEST & EP & $21(84 \%)$ & $4(16 \%)$ & $25(100 \%)$ & \\
& F.A (G1) & EP & $19(76 \%)$ & $6(24 \%)$ & $25(100 \%)$ & 0.5 \\
\hline
\end{tabular}

Table 5. The importance of feedback on the status of the student during the race.

\begin{tabular}{cccccc}
\hline & & & Lax & Twitchy & Total \\
\hline $\begin{array}{c}\text { Initial Performance } \\
\text { (TEST) }\end{array}$ & F.A (G1) & EP & $11(44 \%)$ & $14(56 \%)$ & $25(100 \%)$ \\
$\begin{array}{c}\text { Feedback after } \\
\text { execution (F.A.G1) }\end{array}$ & F.D (G2) & EP & $13(52 \%)$ & $12(48 \%)$ & $25(100 \%)$ \\
\hline
\end{tabular}




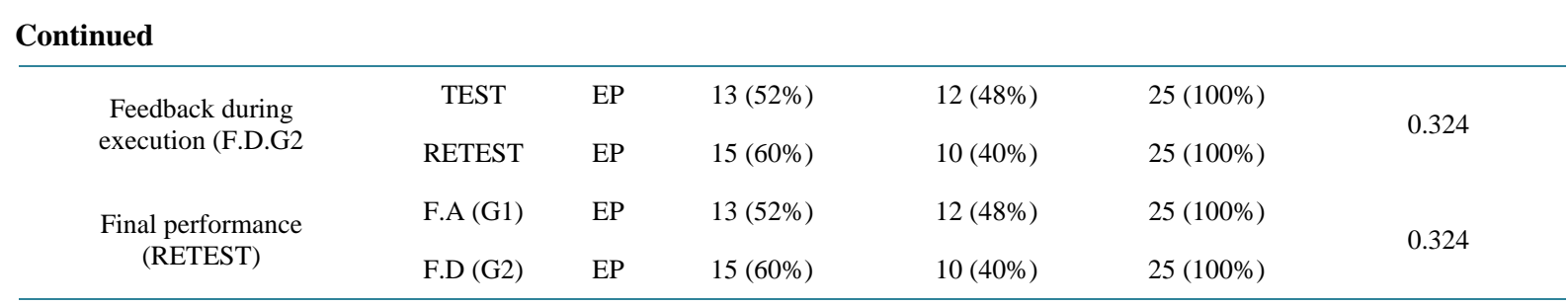

Table 6. Impact of FA and FC before trampling on the board.

\begin{tabular}{ccccccc}
\hline & & & Yes & No & Total & Square Khi \\
\hline $\begin{array}{c}\text { Initial Performance } \\
\text { (TEST) }\end{array}$ & F.A (G1) & EP & $18(72 \%)$ & $7(28 \%)$ & $25(100 \%)$ & 0.44 \\
$\begin{array}{c}\text { Feedback after } \\
\text { execution (F.A.G1) }\end{array}$ & TEST & EP & $18(72 \%)$ & $7(28 \%)$ & $25(100 \%)$ & 8.012 \\
$\begin{array}{c}\text { Feedback during execution } \\
\text { (F.D.G2) }\end{array}$ & RETEST & EP & $8(32 \%)$ & $17(68 \%)$ & $25(100 \%)$ & 3.308 \\
$\begin{array}{c}\text { Final performance } \\
\text { (RETEST) }\end{array}$ & RETEST & EP & $14(56 \%)$ & $11(44 \%)$ & $25(100 \%)$ & $25(100 \%)$ \\
\end{tabular}

Table 7. The relationship between the feedback and the location of the takeoff foot.

\begin{tabular}{ccccccc}
\hline & & & Before the board & Near or on the board & Total & Khi carré \\
\hline $\begin{array}{c}\text { Initial Performance } \\
\text { (TEST) }\end{array}$ & F.A (G1) & EP & $9(36 \%)$ & $16(64 \%)$ & $25(100 \%)$ & 2.012 \\
Feedback after & TEST & EP & $9(36 \%)$ & $11(44 \%)$ & $25(100 \%)$ & $16(64 \%)$ \\
execution (F.A.G1) & RETEST & EP & $6(24 \%)$ & $19(76 \%)$ & $25(100 \%)$ & 0.064 \\
$\begin{array}{c}\text { Feedback during execution } \\
\text { (F.D.G2) }\end{array}$ & TEST & EP & $14(56 \%)$ & $11(44 \%)$ & $25(100 \%)$ & 0.082 \\
$\begin{array}{c}\text { Final performance } \\
\text { (RETEST) }\end{array}$ & RETEST & EP & $13(52 \%)$ & $12(48 \%)$ & $25(100 \%)$ & $25(100 \%)$ \\
\hline
\end{tabular}

the two moments of the employability of feedback since most students (76\% of the first group) place their feet in the zone of appeal against only $52 \%$ of the students of the 2nd group who have placed their appeal feet out of the area. This highlights the importance of didactic and pedagogical intervention after the execution of a motor task, which can guide and facilitate the student's task to identify the calling area.

\subsubsection{Support with Extension of the Call Leg}

From the data presented in Table 8, we find that the feedback placed over or at the end of the motor learning process has an importance on improving the support act since $80 \%$ of the students of the 2nd group have full thrust preparing for the implementation of the next phase (the flight). During this phase (Figure 1), the foot, which executes a scratched movement, promotes the pelvis placement there or is the body's center of gravity, which will decrease the blocking, the pulse then occurs in a very short time with a speed force. Again, the difference is found non-significant between the two moments of feedback (X2 = 2.334).

\subsubsection{Position of the Free Leg}

The statistical analysis presented in Table 9 enables to conclude that the difference is not significant $(\mathrm{KH} 2=$ 0.876) regarding the use of the two moments of intervention. They have the same effect on the angle of the free 


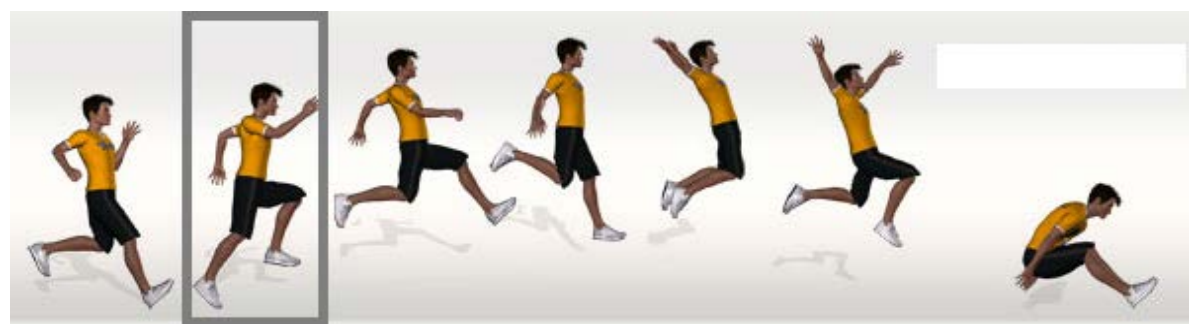

Figure 1. The extension of the call leg.

Table 8. Performance on support with extension of the call leg.

\begin{tabular}{|c|c|c|c|c|c|c|c|}
\hline & & & Complete pushed & Pushed incomplete & Prompted low & Total & Square Khi \\
\hline \multirow{2}{*}{$\begin{array}{l}\text { Initial Performance } \\
\text { (TEST) }\end{array}$} & F.A (G1) & EP & $12(48 \%)$ & $8(32 \%)$ & $5(20 \%)$ & 25 (100\%) & \multirow{2}{*}{0.561} \\
\hline & F.D (G2) & EP & $10(40 \%)$ & $8(32 \%)$ & 7 (28\%) & 25 (100\%) & \\
\hline \multirow{2}{*}{$\begin{array}{c}\text { Feedback after } \\
\text { execution (F.A.G1) }\end{array}$} & TEST & EP & $12(48 \%)$ & $8(32 \%)$ & $5(20 \%)$ & $25(100 \%)$ & \multirow{2}{*}{2.434} \\
\hline & RETEST & EP & 17 (68\%) & $6(28 \%)$ & $2(8 \%)$ & $25(100 \%)$ & \\
\hline \multirow{2}{*}{$\begin{array}{l}\text { Feedback during } \\
\text { exéecution (F.D.G2) }\end{array}$} & TEST & EP & $10(40 \%)$ & $8(32 \%)$ & $7(28 \%)$ & $25(100 \%)$ & \multirow{2}{*}{11.026} \\
\hline & RETEST & EP & $20(80 \%)$ & $5(20 \%)$ & $0 \%$ & $25(100 \%)$ & \\
\hline \multirow{2}{*}{$\begin{array}{l}\text { Final performance } \\
\text { (RETEST) }\end{array}$} & F.A (G1) & EP & 17 (68\%) & $6(28 \%)$ & $2(8 \%)$ & 25 (100\%) & \multirow{2}{*}{2.334} \\
\hline & F.D (G2) & EP & $20(80 \%)$ & $5(20 \%)$ & $0 \%$ & $25(100 \%)$ & \\
\hline
\end{tabular}

Table 9. Impact feedback on position of the free leg.

\begin{tabular}{|c|c|c|c|c|c|c|c|}
\hline & & & Flexion at $90^{\circ}$ & Flexion $<90^{\circ}$ & Flexion $>90^{\circ}$ & Total & Square Khi \\
\hline \multirow{2}{*}{$\begin{array}{l}\text { Initial Performance } \\
\text { (TEST) }\end{array}$} & F.A (G1) & EP & $6(24 \%)$ & $5(20 \%)$ & $14(56 \%)$ & $25(100 \%)$ & \multirow{2}{*}{0.736} \\
\hline & F.D (G2) & $\mathrm{EP}$ & 8 (32\%) & $6(24 \%)$ & $11(44 \%)$ & $25(100 \%)$ & \\
\hline \multirow{2}{*}{$\begin{array}{c}\text { Feedback after } \\
\text { execution (F.A.G1) }\end{array}$} & TEST & EP & $6(24 \%)$ & $5(20 \%)$ & $14(56 \%)$ & 25 (100\%) & \multirow{2}{*}{6.532} \\
\hline & RETEST & $\mathrm{EP}$ & $14(56 \%)$ & $1(4 \%)$ & $10(40 \%)$ & $25(100 \%)$ & \\
\hline \multirow{2}{*}{$\begin{array}{c}\text { Feedback during } \\
\text { execution (F.D.G2) }\end{array}$} & TEST & EP & 8 (32\%) & $6(24 \%)$ & $11(44 \%)$ & $25(100 \%)$ & \multirow{2}{*}{2.518} \\
\hline & RETEST & $\mathrm{EP}$ & $11(44 \%)$ & $2(8 \%)$ & 12 (48\%) & 25 (100\%) & \\
\hline \multirow{2}{*}{$\begin{array}{l}\text { Final performance } \\
\text { (RETEST) }\end{array}$} & F.A (G1) & EP & $14(56 \%)$ & $1(4 \%)$ & $10(40 \%)$ & 25 (100\%) & \multirow{2}{*}{0.876} \\
\hline & F.D (G2) & EP & $11(44 \%)$ & $2(8 \%)$ & 12 (48\%) & $25(100 \%)$ & \\
\hline
\end{tabular}

leg. Similarly, the improvement in both groups between test and retest is remarkable, especially in the first class $(\mathrm{KH} 2=6.532)$.

\subsubsection{Leg Arm-Synchronization}

By examining the data contained in Table 10, we find that the results of the retest have improved in both groups with a percentage from $32 \%$ to $64 \%$ for the first group and $28 \%$ to $60 \%$ for the second group. This leads us to say that students from both groups are making efforts to be better synchronized during movement between the upper limbs and lower limbs to perform a perfect foot-shoulder-basin alignment. This is essential to reduce to a minimum the appearance of a torque causing unsteadiness beforehand.

\subsubsection{Trunk Position}

Using the data shown in Table 11 we are able to see that the trunk position differs from one student to another in both samples, the difference seems small in percentage. It should also be noted that during the phase of the 
Table 10. Impact on the feedback leg arm-synchronization.

\begin{tabular}{|c|c|c|c|c|c|c|}
\hline & & & Yes & No & Total & Square Khi \\
\hline \multirow{2}{*}{$\begin{array}{l}\text { Initial Performance } \\
\text { (TEST) }\end{array}$} & F.A (G1) & EP & 8 (32\%) & 17 (68\%) & 25 (100\%) & \multirow{2}{*}{0.094} \\
\hline & F.D (G2) & EP & 7 (28\%) & 18 (72\%) & $25(100 \%)$ & \\
\hline \multirow{2}{*}{$\begin{array}{c}\text { Feedback after } \\
\text { execution (F.A.G1) }\end{array}$} & TEST & EP & 8 (32\%) & 17 (68\%) & 25 (100\%) & \multirow{2}{*}{5.128} \\
\hline & RETEST & EP & 16 (64\%) & $9(36 \%)$ & 25 (100\%) & \\
\hline \multirow{2}{*}{$\begin{array}{l}\text { Feedback during } \\
\text { execution (F.D.G2) }\end{array}$} & TEST & EP & 7 (28\%) & 18 (72\%) & $25(100 \%)$ & \multirow{2}{*}{5.196} \\
\hline & RETEST & EP & 15 (60\%) & $10(40 \%)$ & 25 (100\%) & \\
\hline \multirow{2}{*}{$\begin{array}{c}\text { Final performance } \\
\text { (RETEST) }\end{array}$} & F.A (G1) & EP & 16 (64\%) & 9 (36\%) & 25 (100\%) & \multirow{2}{*}{0.084} \\
\hline & F.D (G2) & EP & 15 (60\%) & $10(40 \%)$ & 25 (100\%) & \\
\hline
\end{tabular}

\begin{tabular}{|c|c|c|c|c|c|c|c|}
\hline & & & Straight & Leaning forward & Tipped backwards & Total & Square Khi \\
\hline \multirow{2}{*}{$\begin{array}{l}\text { Initial Performance } \\
\text { (TEST) }\end{array}$} & F.A (G1) & EP & $10(40 \%)$ & $9(36 \%)$ & $6(24 \%)$ & $25(100 \%)$ & \multirow{2}{*}{1.13} \\
\hline & F.D (G2) & $\mathrm{EP}$ & 7 (28\%) & $9(36 \%)$ & $9(36 \%)$ & $25(100 \%)$ & \\
\hline \multirow{2}{*}{$\begin{array}{c}\text { Feedback after } \\
\text { execution (F.A.G1) }\end{array}$} & TEST & EP & 10 (40\%) & $9(36 \%)$ & $6(24 \%)$ & $25(100 \%)$ & \multirow{2}{*}{6.91} \\
\hline & RETEST & EP & $12(48 \%)$ & $13(52 \%)$ & $0(0 \%)$ & $25(100 \%)$ & \\
\hline \multirow{2}{*}{$\begin{array}{l}\text { Feedback during } \\
\text { execution (F.D.G2) }\end{array}$} & TEST & EP & 7 (28\%) & $9(36 \%)$ & $9(36 \%)$ & $25(100 \%)$ & \multirow{2}{*}{6.788} \\
\hline & RETEST & EP & $14(56 \%)$ & $9(36 \%)$ & $2(8 \%)$ & 25 (100\%) & \\
\hline \multirow{2}{*}{$\begin{array}{l}\text { Final performance } \\
\text { (RETEST) }\end{array}$} & F.A (G1) & EP & $12(48 \%)$ & $13(52 \%)$ & $(0 \%)$ & $25(100 \%)$ & \multirow{2}{*}{2.882} \\
\hline & F.D (G2) & EP & 14 (56\%) & $9(36 \%)$ & $2(8 \%)$ & 25 (100\%) & \\
\hline
\end{tabular}

retest, there is a slight increase for both classes. This is explained by the fact that it is difficult for beginners to master their trunk for a short act. However, it should be noted that no significant difference in effect is observed between the two moments of the intervention $(\mathrm{X} 2=2.882)$.

\subsection{Analysis of the Qualitative Performance at the Third Phase of the Long Jump: The Flight}

\subsubsection{Orientation of the Flight}

Table 12 shows that there is an increase in the quality of execution for the two classes regarding the employability of the two forms of feedback with a favor for the second group $(p=0.001)$. Indeed, the full and balanced jump depends on the power of the pulse, so the strength of the extensor muscles of the first leg, and the secondary the work of the free leg and arms. For children or beginners, the rope attached to the posts is very effective to control the launch angle and avoid shaving jump.

\subsubsection{Movements of the Upper Limbs}

According to the analysis of the statistical data presented in Table 13, we can distinguish that $64 \%$ of students in the first group show a dynamic movement of the upper limbs (Figure 2) undergoing feedback after performing the driving task against only $44 \%$ the second group having a scheduled feedback after completion of the engine act. The difference appears insignificant as regards the level of effectiveness of two types of interventions.

\subsubsection{Movement of the Lower Limbs}

The results in Table 14 show that G1 improve the quality of the movement of the lower limbs (Figure 3) during the training sessions and the qualitative performance has increased from $24 \%$ to $52 \%$ by using the feedback 


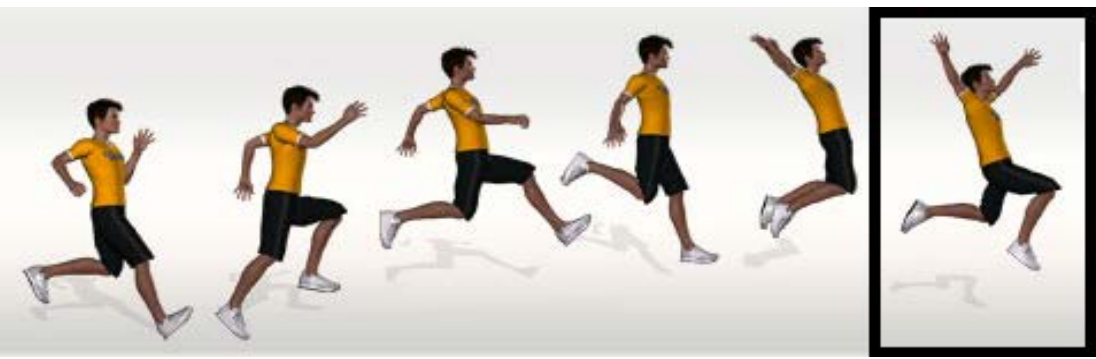

Figure 2. The upper limb movements.

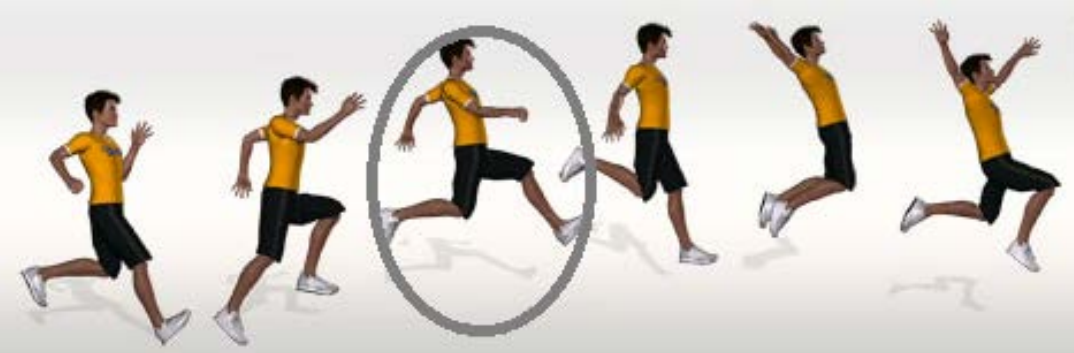

Figure 3. The mobilization of the lower limbs.

Table 12. Impact of two moments of feedback on the angle of the flight.

\begin{tabular}{|c|c|c|c|c|c|c|c|}
\hline & & & Upwards & Forward & Forwardly and upwardly & Total & Square Khi \\
\hline \multirow{2}{*}{$\begin{array}{l}\text { Initial Performance } \\
\text { (TEST) }\end{array}$} & F.A (G1) & EP & $5(20 \%)$ & $12(48 \%)$ & $8(32 \%)$ & $25(100 \%)$ & \multirow{2}{*}{0.94} \\
\hline & F.D (G2) & EP & $8(32 \%)$ & $10(40 \%)$ & $7(28 \%)$ & $25(100 \%)$ & \\
\hline \multirow{2}{*}{$\begin{array}{c}\text { Feedback after } \\
\text { execution (F.A.G1) }\end{array}$} & TEST & EP & $5(20 \%)$ & $12(48 \%)$ & $8(32 \%)$ & $25(100 \%)$ & \multirow{2}{*}{10.03} \\
\hline & RETEST & EP & $1(4 \%)$ & $5(20 \%)$ & 19 (76\%) & $25(100 \%)$ & \\
\hline \multirow{2}{*}{$\begin{array}{l}\text { Feedback during } \\
\text { execution (F.D.G2) }\end{array}$} & TEST & EP & $8(32 \%)$ & $10(40 \%)$ & $7(28 \%)$ & $25(100 \%)$ & \multirow{2}{*}{13.63} \\
\hline & RETEST & EP & $2(8 \%)$ & $3(12 \%)$ & $20(80 \%)$ & $25(100 \%)$ & \\
\hline \multirow{2}{*}{$\begin{array}{l}\text { Final performance } \\
\text { (RETEST) }\end{array}$} & F.A (G1) & EP & $1(4 \%)$ & 5 (20\%) & 19 (76\%) & $25(100 \%)$ & \multirow{2}{*}{0.86} \\
\hline & F.D (G2) & EP & $2(8 \%)$ & $3(12 \%)$ & $20(80 \%)$ & $25(100 \%)$ & \\
\hline
\end{tabular}

Table 13. The influence of the two feedbacks on upper limb movements.

\begin{tabular}{|c|c|c|c|c|c|c|}
\hline & & & Dynamics & Statistics & Total & Square Khi \\
\hline \multirow{2}{*}{$\begin{array}{l}\text { Initial Performance } \\
\text { (TEST) }\end{array}$} & F.A (G1) & EP & $8(32 \%)$ & 17 (68\%) & 25 (100\%) & \multirow{2}{*}{0.0398} \\
\hline & F.D (G2) & EP & $6(24 \%)$ & 19 (76\%) & 25 (100\%) & \\
\hline \multirow{2}{*}{$\begin{array}{c}\text { Feedback after } \\
\text { execution (F.A.G1) }\end{array}$} & TEST & $\mathrm{EP}$ & $8(32 \%)$ & 17 (68\%) & 25 (100\%) & \multirow{2}{*}{5.128} \\
\hline & RETEST & $\mathrm{EP}$ & 16 (64\%) & 9 (36\%) & 25 (100\%) & \\
\hline \multirow{2}{*}{$\begin{array}{c}\text { Feedback during } \\
\text { execution (F.D.G2) }\end{array}$} & TEST & $\mathrm{EP}$ & $6(24 \%)$ & 19 (76\%) & 25 (100\%) & \multirow{2}{*}{2.228} \\
\hline & RETEST & EP & 11 (44\%) & 14 (56\%) & 25 (100\%) & \\
\hline \multirow{2}{*}{$\begin{array}{c}\text { Final performance } \\
\text { (RETEST) }\end{array}$} & F.A (G1) & EP & $16(64 \%)$ & 9 (36\%) & 25 (100\%) & \multirow{2}{*}{2.012} \\
\hline & F.D (G2) & EP & $11(44 \%)$ & 14 (56\%) & 25 (100\%) & \\
\hline
\end{tabular}


Table 14. The importance of feedback on the mobilization of the lower limbs.

\begin{tabular}{|c|c|c|c|c|c|c|}
\hline & & & Dynamics & Statistics & Total & Square Khi \\
\hline \multirow{2}{*}{$\begin{array}{l}\text { Initial Performance } \\
\text { (TEST) }\end{array}$} & F.A (G1) & EP & $6(24 \%)$ & 19 (76\%) & 25 (100\%) & \multirow{2}{*}{0.064} \\
\hline & F.D (G2) & EP & $9(36 \%)$ & 16 (64\%) & 25 (100\%) & \\
\hline \multirow{2}{*}{$\begin{array}{c}\text { Feedback after } \\
\text { execution (F.A.G1) }\end{array}$} & TEST & EP & $6(24 \%)$ & 19 (76\%) & 25 (100\%) & \multirow{2}{*}{4.158} \\
\hline & RETEST & EP & 13 (52\%) & $12(48 \%)$ & 25 (100\%) & \\
\hline \multirow{2}{*}{$\begin{array}{c}\text { Feedback during } \\
\text { execution (F.D.G2) }\end{array}$} & TEST & EP & $9(36 \%)$ & 16 (64\%) & 25 (100\%) & \multirow{2}{*}{0.334} \\
\hline & RETEST & EP & $11(44 \%)$ & 14 (56\%) & 25 (100\%) & \\
\hline \multirow{2}{*}{$\begin{array}{l}\text { Final performance } \\
\text { (RETEST) }\end{array}$} & F.A (G1) & EP & 13 (52\%) & 12 (48\%) & 25 (100\%) & \multirow{2}{*}{0.32} \\
\hline & F.D (G2) & EP & 11 (44\%) & 14 (56\%) & 25 (100\%) & \\
\hline
\end{tabular}

placed after execution the driving task. This increase was noted in the second group (receiving feedback during the learning acquired), but with an extended progression lower than the first and is equivalent to $8 \%$, however, it should be noted that no significant difference in effect is recorded between the two feedback times $(\mathrm{X} 2=0.32)$.

\subsubsection{The Movement of the Trunk}

According to the data collected in Table 15, we can observe a very small improvement in movement of the trunk (Figure 4) in both G1 and G2 respectively, 72\% and 60\% of some students to be used when the feedback is characterized by an uprightness of the trunk. In other cases the trunk is arched in $20 \%$ of students. Furthermore it can be inferred that the movement of the trunk is different from one person to another depending on their physical ability and the used jumping style. Finally no significant difference among F.D and F.A are recorded $(\mathrm{X} 2=1.558)$.

\subsubsection{The Gaze Fixation}

The results of Table 16 infer that there is a progression in the performance of the students during the flight in both groups regardless of when feedback used. Indeed, some students are able to correct their looks forward. This is shown by the percentage of efficiency that has increased from $36 \%$ to $52 \%$ for the first group and $12 \%$ to $44 \%$ for the second. This improvement results in a gain of time during the flight due to the nature of advanced instructions by teachers during motor learning.

\subsection{Analysis of the Qualitative Performance of Pupils in the First Phase of Long Jump: The Fall}

\subsubsection{Positions of the Legs}

The first measurements give the results shown in Table 17 and do not indicate any significant difference between the two groups. Moreover, we note that there is a remarkable improvement in 56\% of the first group of students. During the fall they develop positions grouped and legs bent. This position is very important to reduce the shock when contacting the ground (Figure 5).

\subsubsection{Positions of Arms}

The use of Table 18 allows us to deduce a positive feedback after the scheduled delivery of learners in the G1. This is shown by the value of (X2 = 14.31, $\mathrm{p}=0.01)$. However, we note that the G2, receiving feedback during the learning related to the position of the arm (Figure 6), has not shown significant progress $(\mathrm{X} 2=2.246$ ).

\subsubsection{Trunk Position}

According to statistical data in Table 19, it can be inferred that no significant differences are recorded in the delivery of two groups of learners (KH2 = 2.274). Indeed, we distinguish the performance achieved by both groups at the trunk of the position is positive since more than $75 \%$ of students have expressed an upright position of the trunk or leaning forward. 


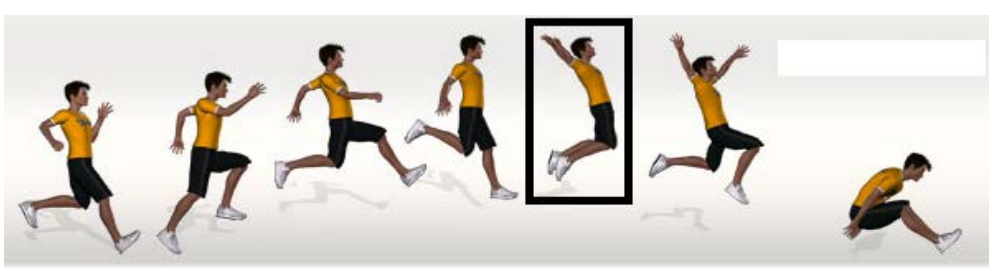

Figure 4. The movements of trunk during the flight.

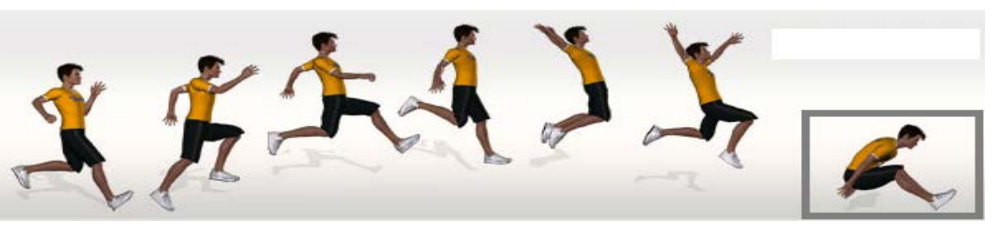

Figure 5. The legs positions.

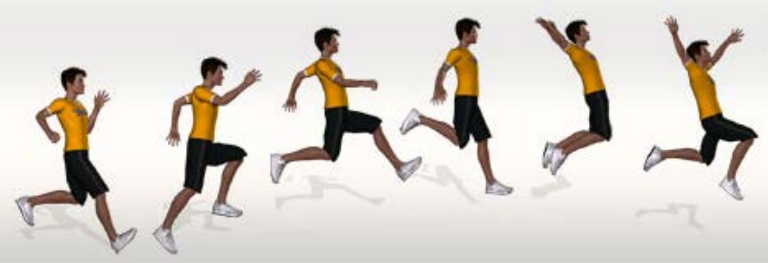

Figure 6. The positions of the arms.

Table 15. Results on the movement of the trunk during the flight.

\begin{tabular}{cccccccc}
\hline & & & Straight & Leaning forward & Tipped backwards & Total & Square Khi \\
\hline $\begin{array}{c}\text { Initial Performance } \\
\text { (TEST) }\end{array}$ & F.A (G1) & EP & $13(52 \%)$ & $6(24 \%)$ & $6(24 \%)$ & $25(100 \%)$ & 1.31 \\
& F.D (G2) & EP & $16(64 \%)$ & $3(12 \%)$ & $6(24 \%)$ & $25(100 \%)$ & \\
$\begin{array}{c}\text { Feedback after } \\
\text { execution (F.A.G1) }\end{array}$ & TEST & EP & $13(52 \%)$ & $6(24 \%)$ & $6(24 \%)$ & $25(100 \%)$ & 2.045 \\
ReedbST & EP & $18(72 \%)$ & $5(20 \%)$ & $2(8 \%)$ & $25(100 \%)$ & $6(100 \%)$ & 0.622 \\
$\begin{array}{c}\text { Fecution (F.D.G2) } \\
\text { Final performance } \\
\text { (RETEST) }\end{array}$ & RETEST & EP & $15(60 \%$ & $5(20 \%)$ & $5(20 \%)$ & $25(100 \%)$ & \\
\hline
\end{tabular}

Table 16. Quality of delivery of groups of learners on the gaze fixation.

\begin{tabular}{|c|c|c|c|c|c|c|c|}
\hline & & & Upwards & Down & Forward & Total & Square Khi \\
\hline \multirow{2}{*}{$\begin{array}{l}\text { Initial Performance } \\
\text { (TEST) }\end{array}$} & F.A (G1) & $\mathrm{EP}$ & $11(44 \%)$ & $5(20 \%)$ & $9(36 \%)$ & 25 (100\%) & \multirow{2}{*}{4.052} \\
\hline & F.D (G2) & EP & $14(56 \%)$ & $8(32 \%)$ & $3(12 \%)$ & 25 (100\%) & \\
\hline \multirow{2}{*}{$\begin{array}{c}\text { Feedback after } \\
\text { execution (F.A.G1) }\end{array}$} & TEST & $\mathrm{EP}$ & $11(44 \%)$ & $5(20 \%)$ & $9(36 \%)$ & 25 (100\%) & \multirow{2}{*}{1.428} \\
\hline & RETEST & EP & 9 (36\%) & $3(12 \%)$ & 13 (52\%) & 25 (100\%) & \\
\hline \multirow{2}{*}{$\begin{array}{c}\text { Feedback during } \\
\text { execution (F.D.G2) }\end{array}$} & TEST & $\mathrm{EP}$ & $14(56 \%)$ & $8(32 \%)$ & $3(12 \%)$ & 25 (100\%) & \multirow{2}{*}{6.572} \\
\hline & RETEST & $\mathrm{EP}$ & $10(40 \%)$ & $4(16 \%)$ & 11 (44\%) & 25 (100\%) & \\
\hline \multirow{2}{*}{$\begin{array}{c}\text { Final performance } \\
\text { (RETEST) }\end{array}$} & F.A (G1) & $\mathrm{EP}$ & $9(36 \%)$ & $3(12 \%)$ & 13 (52\%) & 25 (100\%) & \multirow{2}{*}{0.36} \\
\hline & F.D (G2) & $\mathrm{EP}$ & $10(40 \%)$ & $4(16 \%)$ & $11(44 \%)$ & 25 (100\%) & \\
\hline
\end{tabular}


Table 17. The feedback effect on the legs positions.

\begin{tabular}{|c|c|c|c|c|c|c|c|c|}
\hline & & & $\begin{array}{l}\text { Stretched } \\
\text { on the sand }\end{array}$ & $\begin{array}{l}\text { Grouped } \\
\text { and bent }\end{array}$ & $\begin{array}{c}\text { On } \\
\text { one leg }\end{array}$ & $\begin{array}{l}\text { One bent and the } \\
\text { other extended }\end{array}$ & Total & Square Khi \\
\hline \multirow{2}{*}{$\begin{array}{l}\text { Initial Performance } \\
\text { (TEST) }\end{array}$} & F.A (G1) & EP & $6(24 \%)$ & $4(16 \%)$ & 9 (36\%) & $6(24 \%)$ & 25 (100\%) & \multirow[b]{2}{*}{2.786} \\
\hline & F.D (G2) & EP & 3 (12\%) & 8 (32\%) & 10 (40\%) & $4(16 \%)$ & 25 (100\%) & \\
\hline \multirow{2}{*}{$\begin{array}{c}\text { Feedback after } \\
\text { execution (F.A.G1) }\end{array}$} & TEST & EP & $6(24 \%)$ & 4 (16\%) & 9 (36\%) & $6(24 \%)$ & 25 (100\%) & \multirow[b]{2}{*}{10.768} \\
\hline & RETEST & EP & $3(16 \%)$ & 15 (56\%) & 3 (12\%) & $4(16 \%)$ & 25 (100\%) & \\
\hline \multirow{2}{*}{$\begin{array}{c}\text { Feedback during } \\
\text { execution (F.D.G2) }\end{array}$} & TEST & EP & 3 (12\%) & 8 (32\%) & $10(40 \%)$ & $4(16 \%)$ & 25 (100\%) & \multirow[b]{2}{*}{1.844} \\
\hline & RETEST & EP & $1(0 \%)$ & 10 (40\%) & 8 (32\%) & $6(28 \%)$ & $25(100 \%)$ & \\
\hline \multirow{2}{*}{$\begin{array}{l}\text { Final performance } \\
\text { (RETEST) }\end{array}$} & F.A (G1) & EP & 3 (16\%) & 15 (56\%) & 3 (12\%) & $4(16 \%)$ & 25 (100\%) & \multirow[b]{2}{*}{4.672} \\
\hline & F.D (G2) & EP & $1(0 \%)$ & $10(40 \%)$ & 8 (32\%) & $6(28 \%)$ & $25(100 \%)$ & \\
\hline
\end{tabular}

Table 18. Impact of two points of intervention on the positions of the arms.

\begin{tabular}{|c|c|c|c|c|c|c|c|c|}
\hline & & & Behind the bust & On the sides & grouped & Non grouped & Total & Square Khi \\
\hline \multirow{2}{*}{$\begin{array}{c}\text { Initial } \\
\text { Performance (TEST) }\end{array}$} & F.A (G1) & EP & $8(32 \%)$ & $6(24 \%)$ & $2(8 \%)$ & $9(36 \%)$ & 25 (100\%) & \multirow[b]{2}{*}{2.518} \\
\hline & F.D (G2) & $\mathrm{EP}$ & $4(16 \%)$ & $5(20 \%)$ & $4(16 \%)$ & 12 (48\%) & 25 (100\%) & \\
\hline \multirow{2}{*}{$\begin{array}{c}\text { Feedback after } \\
\text { execution (F.A.G1) }\end{array}$} & TEST & EP & $8(32 \%)$ & $6(24 \%)$ & $2(8 \%)$ & $9(36 \%)$ & $25(100 \%)$ & \multirow[b]{2}{*}{14.31} \\
\hline & RETEST & EP & $4(16 \%)$ & $5(20 \%)$ & $15(60 \%)$ & $3(12 \%)$ & 25 (100\%) & \\
\hline \multirow{2}{*}{$\begin{array}{c}\text { Feedback during } \\
\text { execution (F.D.G2) }\end{array}$} & TEST & EP & $4(16 \%)$ & $5(20 \%)$ & $4(16 \%)$ & 12 (48\%) & 25 (100\%) & \multirow[b]{2}{*}{2.246} \\
\hline & RETEST & EP & $2(8 \%)$ & 7 (28\%) & 7 (28\%) & $9(40 \%)$ & 25 (100\%) & \\
\hline \multirow{2}{*}{$\begin{array}{l}\text { Final Performance } \\
\text { (RETEST) }\end{array}$} & F.A (G1) & EP & $4(16 \%)$ & $5(20 \%)$ & $15(60 \%)$ & 3 (12\%) & 25 (100\%) & \multirow[b]{2}{*}{6.842} \\
\hline & F.D (G2) & EP & $2(8 \%)$ & 7 (28\%) & 7 (28\%) & $9(40 \%)$ & 25 (100\%) & \\
\hline
\end{tabular}

Table 19. The FA and FD impact on the position of the trunk.

\begin{tabular}{|c|c|c|c|c|c|c|c|c|}
\hline & & & Straight & $\begin{array}{l}\text { Leaning } \\
\text { forward }\end{array}$ & $\begin{array}{l}\text { Inclined } \\
\text { on a side }\end{array}$ & $\begin{array}{c}\text { Tipped } \\
\text { backwards }\end{array}$ & Total & Square Khi \\
\hline \multirow{2}{*}{$\begin{array}{l}\text { Initial Performance } \\
\text { (TEST) }\end{array}$} & F.A (G1) & $\mathrm{EP}$ & $8(32 \%)$ & $4(16 \%)$ & $10(40 \%)$ & $3(12 \%)$ & 25 (100\%) & \multirow[b]{2}{*}{5.086} \\
\hline & F.D (G2) & $\mathrm{EP}$ & $10(40 \%)$ & 8 (32\%) & 7 (28\%) & $0(0 \%)$ & 25 (100\%) & \\
\hline \multirow{2}{*}{$\begin{array}{c}\text { Feedback after } \\
\text { execution (F.A.G1) }\end{array}$} & TEST & EP & $8(32 \%)$ & $4(16 \%)$ & $10(40 \%)$ & $3(12 \%)$ & 25 (100\%) & \multirow[b]{2}{*}{3.067} \\
\hline & RETEST & $\mathrm{EP}$ & $10(40 \%)$ & 9 (36\%) & $5(20 \%)$ & $1(4 \%)$ & 25 (100\%) & \\
\hline \multirow{2}{*}{$\begin{array}{l}\text { Feedback during } \\
\text { execution (F.D.G2) }\end{array}$} & TEST & EP & $10(40 \%)$ & $8(32 \%)$ & 7 (28\%) & $0(0 \%)$ & 25 (100\%) & \multirow{3}{*}{1.058} \\
\hline & RETEST & EP & 12 (48\%) & 9 (36\%) & $4(16 \%)$ & $0(0 \%)$ & 25 (100\%) & \\
\hline \multirow{2}{*}{$\begin{array}{c}\text { Final performance } \\
\text { (RETEST) }\end{array}$} & F.A (G1) & $\mathrm{EP}$ & $10(40 \%)$ & $9(36 \%)$ & $5(20 \%)$ & $2(4 \%)$ & 25 (100\%) & \\
\hline & F.D (G2) & $\mathrm{EP}$ & 12 (48\%) & $9(36 \%)$ & $4(16 \%)$ & $0(0 \%)$ & 25 (100\%) & 2.274 \\
\hline
\end{tabular}

\section{Discussion}

Indeed, it is important to note that whatever the methods, feedback embodies a value judgment. The word "judgment" indicates that there is decision making. However, if not arbitrary, judgment is the result from the joint examination of facts, positions. Judge requires the understanding faculty. Thus, the evaluator "judges" the value of work delivered by the learner. He must "decide". To do this, he will rely on his understanding, that is to say, on its own scale of values, values pattern Mason (1996).

The pattern of values of an individual is also personal reflection of the community to which he belongs. Pedagogy, evaluators are members of an educational community that agrees on a vision, approach, methods, and 
evaluation system.

For its part, the goal is to learn to fit more or less to the community. It is based on the "more or less" than the reviewer's value judgments will be felt as legitimate. For more impartial, a judgment must be legitimate. But the legitimacy of course only when there is exchange, dialogue and mutual recognition of rights and duties of each Chiviacowsky \& Wulf (2005). Feedback to learners’ work is part of that dialogue. It illustrates, puts into perspective, and opens in negotiating the quantified result, the grade.

Indeed, it is recalled that the purpose of our research is to highlight the impact of the feedback note on the quality of motor learning for young learners during an athletic activity cycle, namely the long jump. Specifically, we have opted to test the effect related to the time of use of the technical and pedagogical feedback during the teaching act or just after the delivery of the student Chevalier (2004). The analysis of the results allowed us to see the importance of the feedback instrument introduced in the motor learning or after their achievements.

This resulted in improved techniques of executions of the different elements of the jump and the quantitative performance of students in both classes to be doing this experiment. In fact, motor learning considers the feedback as a critical element of the pedagogical relationship, and therefore it should be one of the major concerns of teachers when they are focused on the motor skills to learn (Meisterjahn \& Jensen, 2010). Piéron (1986) admits that continuous progress is only possible through regular knowledge of the results of the practice.

In the same vein, the work of Bilodeau (1969) clearly states that performance can be improved if the feedback is removed. Other authors (Brunelle, 1980; Piéron, 1980; Siedentop, 1994) consider feedback as a very important teaching skill. All these make the ability to provide students with appropriate information about their services a fundamental teaching skill that teachers should possess. Moreover, it is important to point that feedback is first an act of communication. Therefore, the more the transmitter (the assessor) will be able to tailor his message to the receiver characteristics (the learner), the better and the more useful it will be received.

Thus, the evaluator illustrates his point by references that he knows to be common with the learner. Because feedback comes at a particular moment of the learning process, it is expected that the learner plays an important emotional role. A learner is never indifferent to what we think of his work. The appraiser will attach particular importance to the terms and tone of feedback which are, in addition to revealing assessments of the perceived competence, elements of motivation and encouragement.

However, it should be noted that the above mentioned improvements are very remarkable for the first group G1 where the teacher's intervention is programmed after performing a motor task (a growth rate equals to $12.7 \%$ ). By cons in the second group G2 is only noticed a growth rate which equals to $5.77 \%$.

It is important to remember that, the information (feedback) mentioned by the teacher may be for an evaluation of the benefit of the student with "it's good" or "bad," or description of which in whole or in part, or requirement criteria for success of a movement or mistakes to avoid (e.g., Guadagnoli \& Kohl, 2001; Swinnen, 1990; Swinnen, Schmidt, Nicholson, \& Shapiro, 1990; Salmoni, Schmidt, \& Walter, 1984; Schmidt, 1991).

It can still be a question for the student to engage in searching for his mistakes and ways to implement and to fix. Then, this information may be collected by the student orally, visually, tactile, auditory and tactile simultaneously. Then, the information can be addressed to an individual student, group of students or an entire class. Finally, any information may include an emotional message to approving or positive nature which can promote the learning conditions, or an emotional message of disapproval or negativity that could lead to less favorable learning conditions (Piéron, 1986).

The feedback thus encompasses various sizes, and therefore it is a difficult task for the teacher. However, teachers find it more difficult to provide adequate feedback than others. Their teaching experiences of physical education could help overcome these difficulties.

On the other hand, the variety of taught physical activities could also influence the nature of feedback provided to students' dimensions. By cons, in-depth qualitative analysis in the technical components of the long jump (run, call, or drop off and receiving) show that there is an improvement in both groups between the two time points (tests and retests), but the results obtained in this study show non-significant differences between the two moments of feedback except in the case of complex motor tasks execution perspective.

Indeed, we deduced that feedback placed in or at the end of the motor learning process generated a small improvement in the quality of the path of the run in both groups of students.

During this phase you can still see an improvement in inter-segmental coordination between the two moments of evaluation. Indeed, with repetition we can improve the student movements of the arms and legs. But, it remains difficult in the status of the student during the race. Almost $40 \%$ of students have a bad attitude during the 
race. Also, there are $68 \%$ of students have developed without trampling by race after against $44 \%$ in the second group. In this phase the difference was not significant between the two moments of feedback.

During the second phase, most students (76\% of the first group) have set their feet in the zone of appeal against only $52 \%$ of students in the second group who have placed their appeal feet out of the area. This highlights the importance of didactic and pedagogical intervention after the execution of a motor task, which can guide and facilitate the student's task to identify the calling area.

We can say in this sense that practice and exercise conditions can also contribute to a more difficult task to achieve (Battig, 1966; Shea \& Morgan, 1979). It must be understood that the specific sports infrastructure and the level of the learner's ability cannot, by themselves, define the operational difficulty of the task, but they provide a framework for determining the amount of information optimal learning. The repetition exercises can create habits in athletes and correct the attitude of the latter during the pulse: a full thrust (68\% for G1 and 80\% for the second group) with flexion of the free leg nearly $90^{\circ}$ and elevation of the basin. The flight is a very important and decisive phase which depends on the quality of execution of the jump and arm work helps balance and pushes the body forward and lowers limbs. This highlights the efficiency on the assimilation of technical information provided during learning by some students of the time of the use of feedback (Robertson et al., 2004). Indeed, according to Roy (2008) studies on best feedback from developing conditions show that, in general, individuals must be able to assess and correct their own performance to be actively involved in solving engines' problems.

Thus, the training must include accurate and timely feedback made at a frequency designed to encourage learning. Research suggests that learning is enhanced when feedback is not provided to all tests. For example, Schmidt and Wrisberg (2008) demonstrate that the retention is greater than 24 hours after training when the feedback is provided in $50 \%$ of trials in comparison with the same situation, but for which feedback is provided to all tests. In addition, a gradual decrease in the frequency at which feedback is given is an effective way to improve learning. Impose a delay between testing and feedback would not affect learning, as long as the feedback is not presented too soon after the task.

Realizing unrelated to the task activities between the time of the training and the feedback degrades learning. However, the realization of the task related activities, such as subjective estimation of performance, improves learning. It has never been demonstrated that the combination of different types of feedback during training helps or harms motor learning. Studies that have evaluated the best conditions for the application of extrinsic feedback have overwhelmingly rated one type of feedback. By "quality" we mean the potential feedbacks to actively participate in the learning of the learner. We do not establish an exhaustive list of strategies available to tutors or we pretend not to prescribe a universal way to achieve feedback. We hope that the proposals from the analysis of our experience will allow pedagogical frameworks to identify some factors that might encourage learning through feedback and consider them more as a transition point as a term educational dialogue.

\section{Conclusion}

The results of our study confirm that: feedback made after the execution of the task, is more effective than the programmed feedback during the learning process. However, it should be noted that the difference is very significant and remarkable between the two moments of feedback used by PE teachers (Rate of increase in the first group is $12.7 \%$ and it is about $5.87 \%$ for the second group). Faced with these findings, we can only point out to the importance of feedback in motor learning, during or after the completion of the motor task. Indeed, one can also conclude that the feedback as an act of excellence in the teacher's intervention it could be as a key element in the pedagogical relationship, inside the classroom as it is a major concern trainer, especially when they are centered on development and appropriation of professional skills and among future PE Teachers in academic training or even during training. Certainly, we can consider the feedback during the learning engines as a key concept of the quality of technical services. Finally, we can state that the findings of this study are only one attempt to explore the teaching-learning process of physical education. However, it is clear that we need to further more this research by studying the feedback related to the taught activity and characteristics of the tasks of the same activity.

\section{References}

Ammons, R.B. (1996). Effects of Knowledge of Performance: A Survey and Tentative Theoretical Formulation. Journal of General Psychology, 54, 279-299. http://dx.doi.org/10.1080/00221309.1956.9920284 
Battig, W. F. (1966). Facilitation and Interference. In E. A. Bilodeau (Ed.), Acquisition of Skill (pp. 215-244). New York: Academic Press.

Beebe. J. L. (1975). A Comparison of Four Methods of Feedback in the Form of Knowledge of Performance on the Learning of Gymnastic Skills. Completed Research in Health, Physical Education and Recreation, 17, 90.

Bilodeau, E. A., \& Bilodeau, I. M. (Eds.) (1969). Principles of Skill Acquisition. New York: Academic Press.

Brunelle, J.(1980). L'efficacité de l'intervenant dans l'enseignement de l'activité physique. In C. H. Nadeau., W. R. Halliwell, K. M. Newell, \& G. C. Roberts (Eds.), Psychology of Motor Behavior and Sports (pp. 675-689). Champaign, IL: Human Kinetics.

Brunelle, J., Spallanzani, C., Lord M., \& Petiot, B. (1983). Analyse du climat pédagogique par le biais des réactions des éducateurs physiques en situation d'enseignement. Canadian Association for Health Physical Education and Recreation Journal, 49, 15-18, 30.

Chevalier (2004). Apprentissage moteur: cahier d'accompagnement-KIN 2300. Librairie Coop. UQAM.

Chiviacowsky, S., \& Wulf, G. (2005). Self-Controlled Feedback Is Effective If It Is Based on the Learner's Performance. Research Quarterly for Exercise and Sport, 76, 42-48. http://dx.doi.org/10.1080/02701367.2005.10599260

Durand, M. (1992). L'enfant et le sport (3e édition). Paris: Presses universitaires de France.

Fishman, S. E., \& Anderson, W. G. (1971). Developing a System for Describing Teaching. Quest, 15, 9-16. http://dx.doi.org/10.1080/00336297.1971.10519696

Galligan, J. J., LePard, K. J., Schneider, D. A., \& Zhou, X.P. (2000). Multiple mechanisms of fast excitatory synaptic transmission in the enteric nervous system. Journal of the Autonomic Nervous System, 81, 97-103. http://dx.doi.org/10.1016/S0165-1838(00)00130-2

Goldberger, M., \& Gerney, P. (1986). The Effect of Direct Teaching Styles on Motor Skill Acquisition of Fifth Grade Children. Research Quarterly for Exercise and Sport, 57, 215-219. http://dx.doi.org/10.1080/02701367.1986.10605399

Guadagnoli, M. A., \& Kohl, R.,M. (2001). Utilization of Knowledge of Results for Motor Learning: Relationship between Error Estimation and Knowledge of Results Frequency. Journal of Motor Behavior, 33, 217-224. http://dx.doi.org/10.1080/00222890109603152

Magill, R. A. (2011). Motor Learning and Control: Concepts and Applications (9th ed.). New York: McGraw Hill.

Mason, J. (1996) Expressing Generality and Roots of Algebra. In N. Bednarz, C. Kieran, \& L. Lee (Eds.), Approaches to Algebra: Perspectives for Research and Teaching (pp. 65-86), Dordrecht: Kluwer Academic Publishers. http://dx.doi.org/10.1007/978-94-009-1732-3_5

Nicaise, V., Cogérino, G., Bois, J., \& Amorose, A. J. (2006). Students’ Perceptions of Teacher’s Feedback and Physical Competence in Physical Education Classes: Gender Effects. Journal of teaching in Physical Education, 25, 36-57.

Petracek, R. J. (1978). The Effect of Three Assessment Feedback Schedules on Attitude toward Physical Activity and Self Concept. Completed Research in Health, Physical Education and Recreation, 20, 283-284.

Piéron, M. (1980). Feedback (Rétroaction) et modification du comportement des apprenant: analyse en situation d'enseignement. In C. H. Nadeau., W. R. Halliwell, K. M. Newell, \& G. C. Roberts (Eds.), Psycholoogy of Motor Behavior and Sport (pp. 526-534). Champaign, IL: Human Kinetics.

Piéron, M. (1986). Enseignement des activités physiques. Observation et recherche. Liège: Presses Universitaires de Liège.

Piéron, M. (1992). Pédagogie des activités physiques et du sport, Ed. Revue EPS, Paris.

Piéron, M., \& Devillers, C. (1980). Multidimensional Analysis of Informative Feed-Back in Teaching Physical Activities. In: G. Chilling, \& W. Baur (Eds.), Audiovisual Medium in Sport. Moyens audiovisuels dans le sport. Audiovisual means in sport, base (pp. 277-284). City name: Birkhauser Verlag.

Prato, D. J. (1975). The Effects of Three Terminal Augmented Feedback Conditions upon the Acquisition of Motor Skill in Bowling. Dissertation Abstracts International, 36, 6537.

Robertson, E. M., Pascual, L., \& Miall, R. C. (2004). Concepts in procedural consolidation. Nat Rev Neurosci., 5, $576-582$. Http://Dx.Doi.Org/10.1038/Nrn1426

Salmoni, A., Schmidt, R. A., \& Walter, C. B. (1984). Knowledge of Results and Motor Learning: A Review and Critical Reappraisal. Psychological Bulletin, 95, 355-386. http://dx.doi.org/10.1037/0033-2909.95.3.355

Schmidt, R. A. (1991). Frequent Augmented Feedback Can Degrade Learning: Evidence and Interpretations. In. J. Requin, \& G. E. Stelmach (Eds.), Tutorials in Motor Neuroscience (pp. 59-75). Amsterdam: Kluwer Academic. http://dx.doi.org/10.1007/978-94-011-3626-6_6

Schmidt, R. A., \& Wrisberg, C. A. (2008). Motor Learning and Performance: A Situation-Based Learning Approach (4th ed.). Champaign, IL: Human Kinetics. 
Shea, J. B., \& Morgan, R. L. (1979). Contextual Interference Effects on the Acquisition, Retention, and Transfer of a Motor Skill. Journal of Experimental Psychology: Learning, Memory and Cognition, 5, 179-187. http://dx.doi.org/10.1037/0278-7393.5.2.179

Siedentop, D. (1994). Apprendre à enseigner l'éducation physique. Montmagny: Edition Marquis.

Swinnen, S. P., Schmidt, R. A., Nicholson, D. E. \& Shapiro, D. C. (1990). Information Feedback for Skill Acquisition: Instantaneous Knowledge of Results Degrades Learning. Journal of Experimental Psychology: Learning, Memory and Cognition, 16, 706-716. http://dx.doi.org/10.1037/0278-7393.16.4.706 